\title{
Outcome of mitral valve repair or replacement for non-ischemic mitral regurgitation: a systematic review and meta-analysis
}

\author{
Qianqian Fan ${ }^{1,2+}$, Xiaoguang $\mathrm{Li}^{1,3+}$, Guilan Cao ${ }^{1}$, Puliang $\mathrm{Yu}^{4^{*}}$ and Fengxiao Zhang ${ }^{1 *}$ (D)
}

\begin{abstract}
Background: Mitral regurgitation (MR) is a rather common valvular heart disease. The aim of this systematic review and meta-analysis was to compare the outcomes, and complications of mitral valve (MV) replacement with surgical MV repair of non-ischemic MR (NIMR)

Methods: MEDLINE, EMBASE, and the Cochrane Central Register of Controlled Trials were searched until October, 2020. Studies were eligible for inclusion if they included patients with MR and reported early (30-day or in-hospital) or late all-cause mortality. For each study, data on all-cause mortality and incidence of reoperation and operative complications in both groups were used to generate odds ratios (ORs) or hazard ratios (HRs). This study is registered with PROSPERO, CRD42018089608.

Results: The literature search yielded 4834 studies, of which 20 studies, including a total of 21,898 patients with NIMR, were included. The pooled analysis showed that lower age, less female inclusion and incident of hypertension, significantly higher rates of diabetes and atrial fibrillation in the MV replacement group than MV repair group. No significant differences in the rates of pre-operative left ventricle ejection fraction (LVEF) and heart failure were observed between groups. The number of patients in the MV repair group was lower than in the MV replacement group. We found that there were significantly increased risks of mortality associated with replacement of MR. Moreover, the rate of re-operation and post-operative MR in the MV repair group was lower than in the MV replacement group.
\end{abstract}

Conclusions: In patients with NIMR, MV repair achieves higher survival and leads to fewer complications than surgical MV replacement. In light of these results, we suggest that MV repair surgery should be a priority for NIMR patients.

Keywords: Non-ischemic mitral regurgitation, Mitral valve repair, Mitral valve replacement, Meta-analysis

\footnotetext{
*Correspondence: rupolo2006@126.com; xiaoyou_321@foxmail.com

${ }^{\dagger}$ Qianqian Fan and Xiaoguang Li contributed equally as co-first authors.

${ }^{4}$ Key Laboratory of Metallurgical Equipment and Control Technology, Wuhan

University of Science and Technology, Hubei Province 430081, China

'Department of Cardiology, Union Hospital, Tongji Medical College,

Huazhong University of Science and Technology, Hubei Province 430022,

China

Full list of author information is available at the end of the article
}

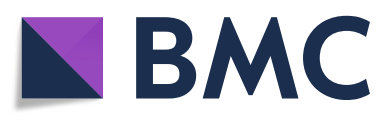

(0) The Author(s). 2021 Open Access This article is licensed under a Creative Commons Attribution 4.0 International License, which permits use, sharing, adaptation, distribution and reproduction in any medium or format, as long as you give appropriate credit to the original author(s) and the source, provide a link to the Creative Commons licence, and indicate if changes were made. The images or other third party material in this article are included in the article's Creative Commons licence, unless indicated otherwise in a credit line to the material. If material is not included in the article's Creative Commons licence and your intended use is not permitted by statutory regulation or exceeds the permitted use, you will need to obtain permission directly from the copyright holder. To view a copy of this licence, visit http://creativecommons.org/licenses/by/4.0/ The Creative Commons Public Domain Dedication waiver (http://creativecommons.org/publicdomain/zero/1.0/) applies to the data made available in this article, unless otherwise stated in a credit line to the data. 


\section{Introduction}

Mitral regurgitation (MR) is a rather common form of mitral valve (MV) dysfunction, occurring in approximately $10 \%$ of the population [1]. Normal mitral closure depends on the integrity and normal function of five components: the leaflets, annulus, tendons, papillary muscles, and left ventricle. Abnormalities in the structure and function of any one of these five components can lead to MR. Patients with mild MR have only occasional exertional dyspnea, and can be asymptomatic. However, acute severe MR (e.g., papillary muscle rupture) can lead to acute left heart failure or even cardiac death.

Severe MR often requires surgical correction, which is useful for improving the prognosis and quality of life of the patients. Traditionally, MV surgery for mitral regurgitation consists mainly of MV replacement and MV repair. According to several lines of evidence from comparative studies, MV repair, which has been increasingly more often performed since 1980s, is preferred over MV replacement [2], and currently, more and more patients benefit from successful valve repair operations. However, whether to replace or repair severe MR, remains a controversial topic. Previously, the majority of surgeons believed that MV repair was of low surgical risk, with few near and long-term adverse events, and offered optimal survival environment and quality of life; therefore, and given its ability to preserve the heart's natural structure intact and achieve optimal cardiac functional reserve, it became the preferred surgical treatment modality for mitral valve disease. However, there are still questions about the durability of mitral valve repair due to conceptual, technical, and real-world limitations. Moreover, recent data comparing MV repair and replacement failed to demonstrate superiority of $\mathrm{MR}$ repair in ischemic MR patients [3]. Altogether, these findings challenge the benefits and the superiority of MV repair over replacement.

The etiology of MR is heterogeneous and may lead to outcome bias after valve surgery. There are many causes of MR, including rheumatic fever, coronary heart disease, congenital valve malformations, and mitral valve degeneration. In addition, ischemic mitral valve insufficiency is a complex condition, with several associated issues as the need for revascularization, susceptibility to comorbid ventricular wall tumors or myocardial scars, and severe left heart dysfunction [4]. In this study, we selected studies that included patients with non-ischemic mitral valve insufficiency. We performed a systematic review and a meta-analysis comparing clinical results of isolated MV surgery in patients with non-ischemic MR (NIMR).

\section{Methods}

\section{Standard of systematic reviews}

This study is designed and performed according to the "Transparent reporting of systematic reviews and meta- analyses" (PRISMA) guidelines (see Supplemental material). This systematic review and meta-analysis have been registered with the International Prospective Register of Systematic Reviews (PROSPERO, ID: CRD42018089608).

\section{Search strategy}

We systematically searched for studies, including randomized controlled trials (RCTs) and observational comparative studies, of surgical MV replacement versus surgical MV repair that enrolled patients with NIMR. Databases including MEDLINE, EMBASE, and the Cochrane Central Register of Controlled Trials were searched from inception to October, 2020 using Webbased search engines (PubMed and OVID). The search strategies employed a number of free-text keywords as well as controlled vocabulary terms (see Appendix A for actual search strategies).

\section{Selection criteria and data abstraction}

Studies were considered for inclusion if they met the following criteria: the design was a RCT or observational comparative study and the study population included patients with NIMR; patients were assigned to MV replacement versus MV repair; and main outcomes reported included early (30-day or in-hospital) or late $(\geq 6$ month including early) all-cause mortality. Data regarding detailed inclusion criteria, baseline patient profiles, duration of follow-up, all-cause mortality, and etiology of MR were abstracted (as available) from each individual study.

\section{Data extraction and risk of bias assessment}

One investigator (F-X.Z.) used a standardized form to extract the following relevant data and another investigator (P-L.Y.) independently confirmed their accuracy. Disagreement was resolved by discussion with another investigator (QQ. F.). The study quality was assessed using a previously proposed scale (newcastle-ottawa scale) $[5,6]$. A greater overall score indicated a lower risk of bias; a score of 5 or less (of 9) suggested a high risk of bias. Risk of bias also was evaluated independently by two authors(G-L.C. and QQ. F.).

\section{Statistical analysis}

We conducted a meta-analysis of summary statistics from the individual studies. We generated mean differences (MDs) and 95\% confidence intervals (CIs) using means (with standard deviations) of age, left ventricle ejection fraction (LVEF) in both the MV replacement and MV repair groups, as well as risk (rate) differences (RDs) using rates of female patients, patients with diabetes, hypertension, heart failure, and New York Heart Association (NYHA) functional class $(\geq \mathrm{III})$ in both 
groups. HR and 95\% CIs were used to estimate the effect of the intervention on patient survival.

If $\mathrm{HR}$ and $95 \% \mathrm{CI}$ values were not available, KaplanMeier curves were read using Engauge Digitizer version 4.1, and the survival data were then entered in the spreadsheet based on previous work by Liu et al. [7]. Summary HRs (for total survival) and the summary ORs (for 30-day survival and re-operation) were directly abstracted from each study. For a study without available HRs, an HR was calculated based on the Kaplan-Meier curve [8] or summary data using the methods by Parmar et al. [9]. Heterogeneity among the included studies was assessed by Cochran's $Q$ statistics and by $\mathrm{I}^{2}$ test. If significant heterogeneity was obtained on analysis, we used reported cut-off values (> 50\% mild, 51 to $75 \%$ moderate, and $>75 \%$ significant) and the random-effects model; otherwise, we used the fixed model. Publication bias was assessed visually on a funnel plot and statistically using a mixed-effects Egger's test. All analyses were conducted using Review Manager version 5.3 [REFERENCE or weblink].

\section{Results}

\section{Search results}

Our search identified 4834 studies and 20, enrolling a total of 21,898 patients with NIMR, were included in the final analysis (Table S1 \& Fig. 1) [2, 10-26]. Four studies were retrospective [11-13,21], two were case-control studies $[15,20]$, and 14 studies were prospective cohort studies. Two studies exclusively enrolled hypertrophic obstructive cardiomyopathy patients with MR [13, 14] and two studies included only Marfan syndrome cases with MR $[15,16]$, whereas four studies excluded ischemic MR [10, 11, 23, 24]. Eleven studies enrolled patients with degenerative MR. The mean follow-up duration was from 30 days [27] to more than 10 years [13]. When
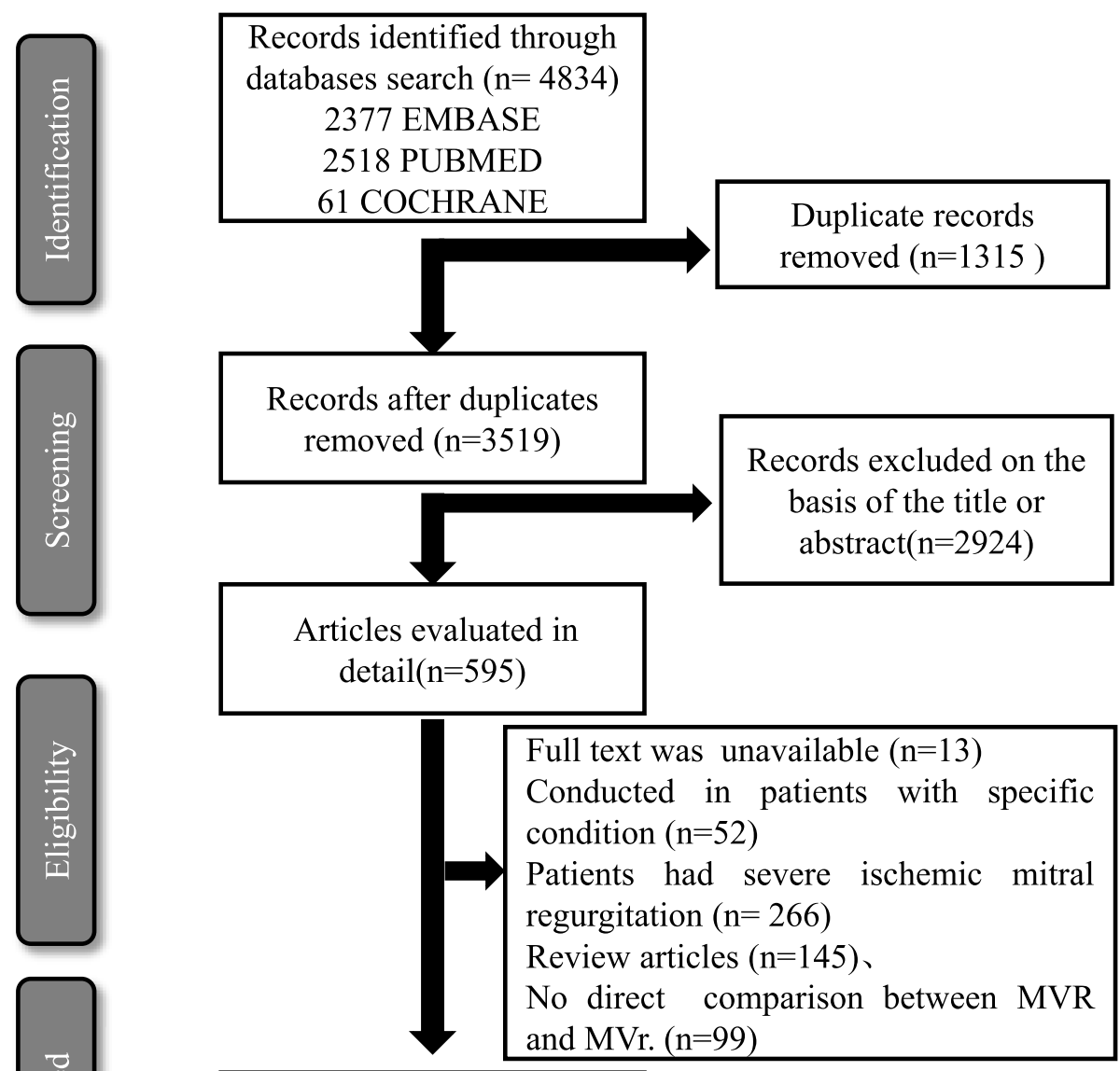

Studies included in the systematic review and meta-analysis $(\mathrm{n}=20)$ 
available, prevalence of risk factors of surgery for each study is given in Table S2. These risk factors included heart failure (New York Heart Association (NYHA) class III or IV, low pre-operative LVEF), and prior history of hypertension, diabetes, or atrial fibrillation.

\section{Quality assessment}

The quality assessment of the 20 included studies is shown in Table S3. According to the Newcastle-Ottawa Scale to assess the risk of bias in these studies, 17 studies scored between 6 and 9, indicating high methodologic quality. The remaining three studies scored ...

\section{Patient profiles}

Age

Fifteen studies provided exact values for mean age of two groups. The average age in most of the studies was between 50 and 78 years (Table S1). There was a study reported using younger patients [15]; while another study used very elderly subjects [12]. A pooled analysis demonstrated that patients of MV repair group were slightly younger than the ones in the MV replacement group (1.92; [1.74, 2.11]; $\mathrm{p}=<0.0001$; Supplemental Fig. S1).

\section{Gender}

Fourteen studies provided exact numbers of women for two groups. Most studies included more male patients than female. The percentage of women included was substantially higher than men only in two studies (Table S2) [14, 27]. The percentage of women included was lower in the MV repair group than in the MV replacement group (1.37; [1.28, 1.47]; $p<0.0001$; Supplemental Fig. S2).

\section{Pre-operative cardiac function}

Only six of the 20 studies provided precise values of preoperative LVEF for two groups. Eleven studies supplied the numbers of NIMR patients with NYHA functional class $(\geq \mathrm{III})$, and three studies disclosed the numbers of NIMR patients with heart failure. Our results demonstrate that there was no difference in number of preoperative LVEF $(0.03,[-0.16,0.23] ; p=0.01$, Supplemental Fig. S3A), or heart failure (1.02, [0.77, 1.35]; $p=$ 0.87, Supplemental Fig. S3C) between the two groups, but the number of individuals of NYHA functional class ( $\geq$ III) in the MV repair group was slightly lower than in the MV replacement group $(1.19,[1.01,1.41] ; p=$ 0.0009, Supplemental Fig. S3B).

\section{Risk factors}

Only five of the 20 studies provided exact numbers of patients with diabetes for the two groups. Six studies disclosed the numbers of NIMR patients with hypertension, and 11 studies disclosed the numbers of MR patients with atrial fibrillation (AF). The rate of diabetes (3.04, [2.03, 4.54]; $p=0.003$, Supplemental Fig. S4A), hypertension $(1.45,[1.33,1.58] ; p<0.00001$, Supplemental Fig. S4B) and AF (1.31, [1.22, 1.41]; $p=0.50$, Supplemental Fig. S4C) were lower in the MV repair group than in the MV replacement group.

\section{Outcomes \\ Early mortality}

OR for early mortality was available for 12 articles. However, these studies were not fully consistent in their definition of early mortality. For the purpose of the current analysis, early outcomes labeled 'early mortality' $(n=1)$, 'hospital mortality' $(n=2)$, 'operative mortality' $(n=5)$, and '30-day mortality' $(n=4)$ were combined under the 'early mortality' label. There was no early mortality among the patients in one of the studies [16]. Unadjusted ORs for early mortality were available for 11 studies, two of which suggested a significantly lower early-mortality rate in the MV repair group than in the MV replacement group [12, 23]. The pooled analysis of these studies showed a summary OR of 2.72 ([2.28, 3.24]; $p<0.00001$ ), suggesting that people in the MV replacement group have a significantly increased risk of early mortality compared to people in the MV repair group (Fig. 2). Studies included subgroups according to the etiology of MR, and seven of these studies specifically focused on degenerative MR. The heterogeneity test was not statistically significant $\left(p=0.09, \mathrm{I}^{2}<50 \%\right)$ for the degenerative subgroup, nor for the other included studies, suggesting no clear evidence of a major discrepancy among the ORs for the studies analyzed.

\section{Late survival}

HR for late mortality was available in 10 articles, four of which provided the adjusted $\operatorname{HR}[2,18,24,28]$. HR for 20 years survival was provided in two studies $[2,18]$, one study provided 6 years survival data [25], one study provided 5 years survival data [21], while 10 year survival HR was available in five articles $[13,15,19,24,26,28]$. A pooled analysis indicated statistically higher latemortality rate in the MV replacement group than in the MV repair group (1.81, [1.59, 2.07]; $p=0.56$, Fig. 3). Studies included subgroups according to the etiology of $M R$, and seven of these studies focused on degenerative MR. The heterogeneity test was not statistically significant $\left(p>0.10, \mathrm{I}^{2}<50 \%\right)$ for the degenerative subgroup, nor for the other included studies, suggesting no clear evidence of a major discrepancy among the hazard ratios for the studies analyzed.

\section{Reoperation}

Nine articles provided information to allow determination of the re-operative $\mathrm{OR}$ for $\mathrm{MV}$ replacement 


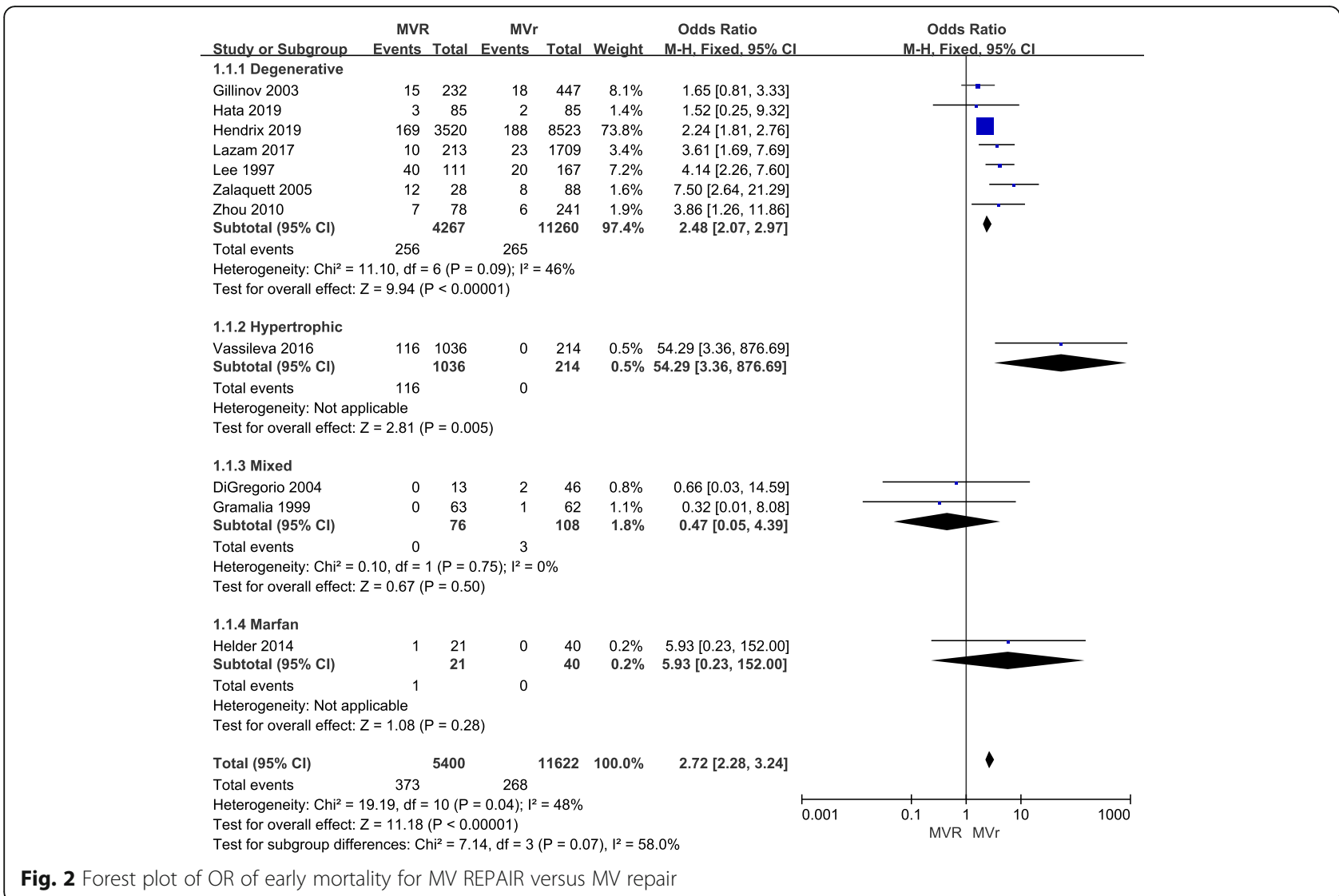

Fig. 2 Forest plot of OR of early mortality for MV REPAIR versus MV repair

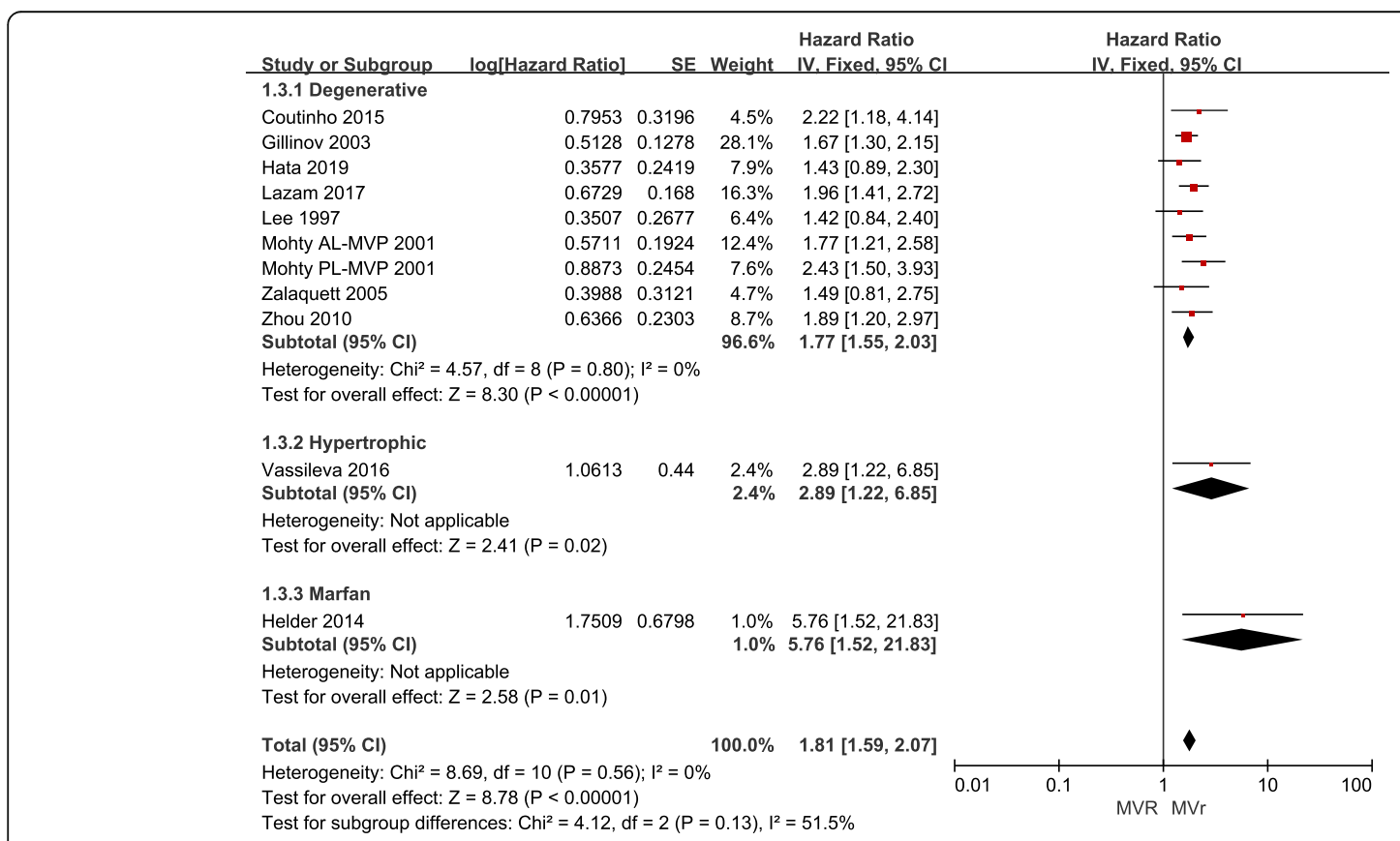

Fig. 3 Forest plot of HR of late mortality for MV REPAIR versus MV repair 
relative to repair. Results demonstrated that the risk of reoperation is higher in MV replacement group than in MV repair group (1.59; [1.36, 1.86]; $p=0.22$; Fig. 4).

\section{Complications}

Major complications of MV surgery were post-operative MR (including residual or recurrent MR), thromboembolism, heart failure, infective endocarditis. No sufficient information for determining the hazard ratio for development of these complications was provided in the studies.

Data on post-operative severe MR were analyzed. Only four articles provided exact numbers of post-operative MR in the two groups. Our results suggest that the incidence rate of post-operative severe MR was lower in the MV repair group than in the MV replacement group (1.43; $[1.13,1.82] ; p=0.01$; Fig. S5). Additional postoperative complications were studied in only two articles $[23,25]$, both of which suggested beneficial effects from repair compared to replacement for thromboembolism and heart failure. One study [23] demonstrated that more patients had infective endocarditis in the MV replacement group than in the MV repair group, while another study [25] suggested a comparable incidence rate of infective endocarditis in the two groups.

\section{Publication bias}

Inspection of the funnel plot (Fig. 5) did not show significant asymmetry for early and late mortality, suggesting that publication bias in unlikely to have influenced the results.

\section{Discussion}

The current meta-analysis is an attempt to pool basic available information on the outcome experience of the two treatment methods for NIMR, specifically defined as MV repair and MV replacement. We included 20 studies, comprising a total of 21,898 patients. We demonstrate a statistically significant early and late survival benefit for patients who have undergone MV repair vs MV replacement. MV repair also led to a lower rate of re-operation and post-operative MR than surgical MV replacement. However, there was insufficient information for determining the hazard ratio of other surgery complications. In line with our findings, a number of articles previously indicated that the post-operative risk of thromboembolism and heart failure was lower for MV repair compared to MV replacement [23, 25].

It is generally regarded that the outcome after MV repair is better than that after MV replacement, and indeed valve repair operation has become the first choice in patients with MV diseases [29,30]. In agreement with previously published data, we found that early and late mortality rates of NIMR in the MV repair subgroup significantly favored the repair group. Many experts believe that mitral valve replacement is superior to mitral valve replacement in the recovery of cardiac function due to the reasons of retaining chordae tendinae. However, the present findings should be interpreted with caution, because of higher risk profiles (high rates of diabetes and $\mathrm{AF}$ ) in the MV repair than in the surgical MV replacement group. Previous studies suggested that diabetes and AF are associated with significantly worse outcomes after valve operations [31, 32]. Rates of diabetes and AF can also affect the heart function of NIMR patients. Even so, higher survival rates in the MV repair group than in surgical MV replacement for NIMR suggest survival benefits after MV repair, despite higher risk profiles of the patients included in this group.

Different etiologies can affect different mitral apparatus and lead to various pathologic alterations and outcomes [33]. Common causes of MR are congenital cleft MV, rheumatic heart disease, MV prolapse, infective endocarditis, rupture of chordae tendineae, Marfan syndrome, hypertrophic cardiomyopathy, endocardial fibrosis, and ischemic heart disease [34]. This systematic review summarizes characteristics and outcomes in patients with degenerative, hypertrophic, Marfan and mixed mitral valve regurgitation. Most of the include studies enrolled a cohort of patients with degenerative subjects. MV repair exhibited a survival advantage in in comparison to MV replacement. More articles are

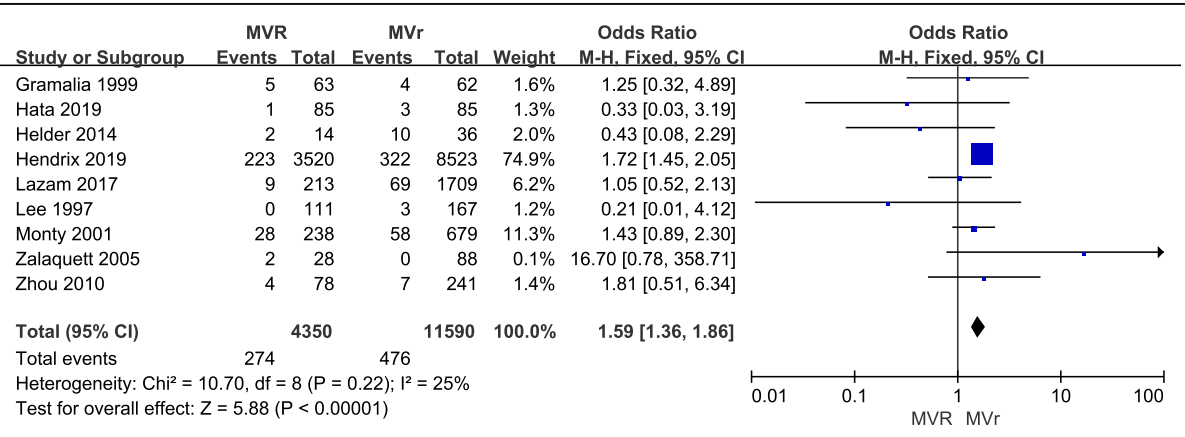

Fig. 4 Forest plot of OR of re-operation for MV REPAIR versus MV repair 


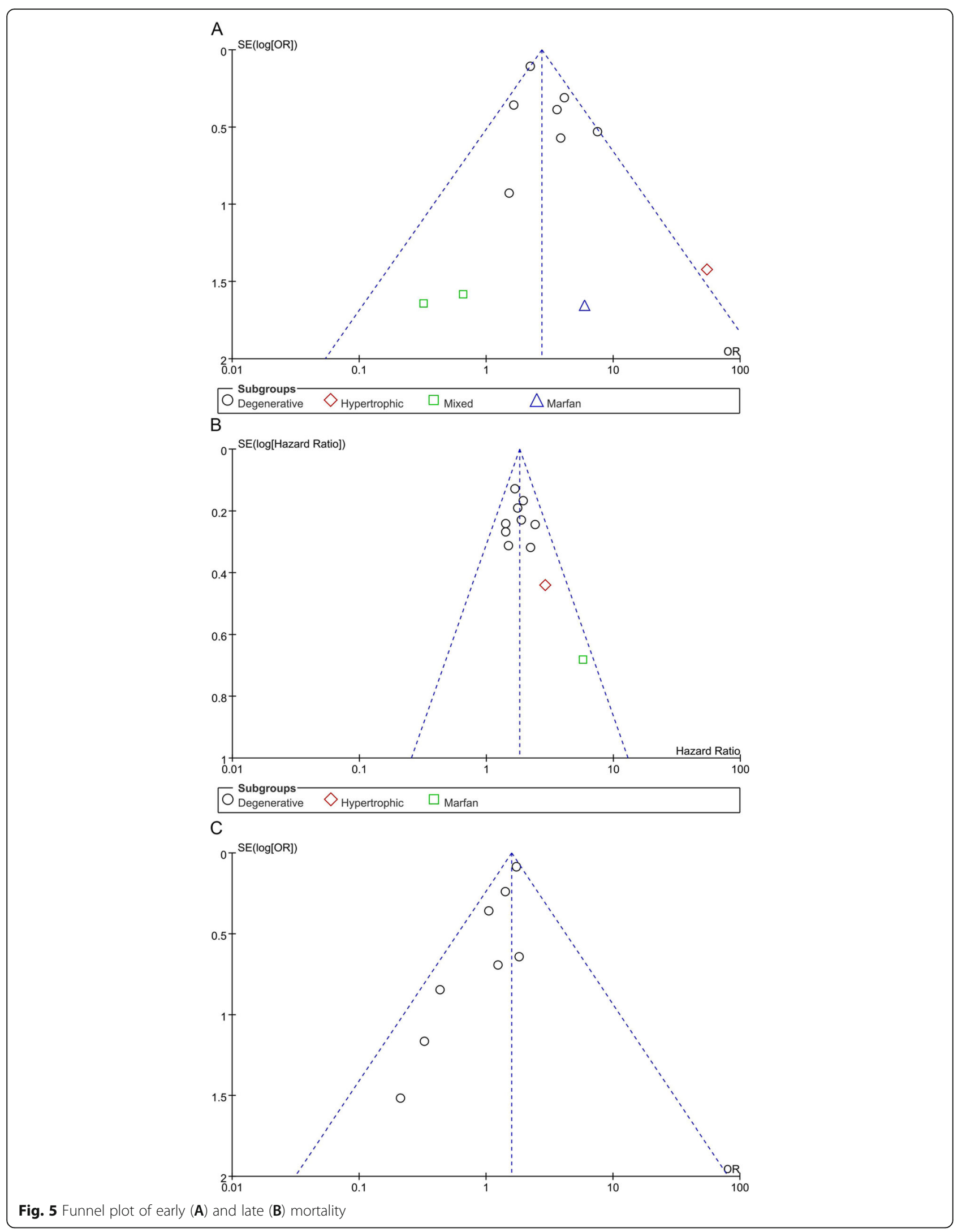


needed for a comprehensive analyzes of benefits of MV repair in different conditions.

In this systematic review, and meta-analysis we found that the risk of re-operation was higher in the MV replacement than in the repair group. Theoretically, patients who had unsuccessful valve repair should have worse outcomes than those who underwent direct mitral valve replacement due to the increased complexity of repair surgery and longer cardiopulmonary bypass time $[35,36]$. Knowledge of the risk factors for the failure of $\mathrm{MV}$ is critical to help reduce the rates of reoperation. Reasons for reoperation included technical mistakes and valverelated causes (e.g. infection, progression of disease, and thrombosis). The main reason of re-operation in patients with NIMR was post-operative MR, including residual or recurrent MR [37]. In this review and meta-analysis, the incidence rate of post-operative MR was higher in MV replacement than in the MV repair group. The main mechanism of recurrent regurgitation after MV repair is progressive degeneration. Surgical repair procedures differed in some details, according to method of annuloplasty (suture vs. ring), type of ring annuloplasty (flexible or rigid), and chordal modification (transposition, shortening and replacement) [29]. Variations could help to improve the effect of surgery and minimize valvular failure. Zhou et al. identified the following factors as having an influence on the durability of repair for degenerative mitral valve disease: age $<60$ years, ring size $(\mathrm{mm})$ /body surface area $\left(\mathrm{m}^{2}\right) \geq 19.0$, absence of a prosthetic ring and residual mitral regurgitation $(\geq 1$ / 4 ) at the end of surgery [21]. The selection of a surgical procedure (repair vs. replacement) is a multifactorial process that involves the surgeon, the patient and institution. The findings provided in this systematic review and meta-analysis help provide guidance regarding the best type of approach for each patient.

\section{Limitations}

The results are based on data pooled from retrospective, case-control and prospective cohort studies, but no RCT studies were included. The study by Hendrix and colleagues [27], which included 12,043 subjects, carried disproportionate weight in the analysis of the results. Moreover, most studies collected subjects with degenerative NIMR. Therefore, biases are likely to have occurred due to the different type, weight and etiology of the studies included, and for this reason the results presented here should be interpreted with caution. In addition, more studies are needed to supply sufficient information to quantify the effect of etiology and the HR for surgery complications.

\section{Conclusions}

In conclusion, repair surgery for NIMR was associated with a lower 30-day mortality and higher survival than replacement despite risk profiles (higher rate of diabetes and AF in the repair group). We observed lower rates of re-operation and post-operative MR in the repair group of non-ischemic mitral valve. However, etiology-related differences in the risk of re-operation remain uncertain and further studies and trials are needed. The results of this systematic review and meta-analysis can provide guidance for doctors and patients regarding the choice of mitral valve surgery and help to predict outcomes of NIMR patients.

\section{Abbreviations}

Cls: Confidence intervals; HRs: Hazard ratios; LVEF: Left ventricle ejection fraction; MR: Mitral regurgitation; MV: Mitral valve; NIMR: Non-ischemic MR; MDs: Mean differences; NYHA: New York Heart Association;

RCTs: Randomized controlled trials; RDs: Differences; ORs: Odds ratios

\section{Supplementary Information}

The online version contains supplementary material available at https://doi. org/10.1186/s13019-021-01563-2.

Additional file 1: Table S1 Demographic information on included studies. Table S2 Risk factors of patients undergoing mitral valve versus replacement. Table S3. Quality ratings for the cohort studies included on the basis of Newcastle-Ottawa quality assessment scale.

Additional file 2.

Additional file 3 .

Additional file 4.

Additional file 5 .

Additional file 6 .

\section{Acknowledgements}

The authors declare no competing financial interests.

\section{Authors' contributions}

Fengxiao zhang designed the study. Qianqian Fan, Xiaoguang Lia screened studies and extracted data. Disagreements were resolved by discussion with Guilan Cao. Qianqian Fan and Puliang Yu did the statistical analyses and prepared figures. Puliang Yu and Fengxiao Zhang reviewed the results, interpreted data, and wrote the manuscript. All authors saw and approved the final version of the paper.

\section{Funding}

This work was supported by National Natural Science Foundation of China [number 81400303, 51705378 and 81700332], and Postdoctoral Sustentation Fund of China [number 2017 M622532].

\section{Availability of data and materials}

The datasets used and analyzed during the current study are available from the corresponding author on reasonable request.

\section{Declarations}

Ethics approval and consent to participate

The Ethical Committee of the Tongji Hospital, Tongji Medical College, Huazhong University of Science and Technology, Wuhan, China, reviewed and approved our study protocol. Since the study is a meta-analysis, informed consent was waived.

Consent for publication

Not applicable. 


\section{Competing interests}

The authors have nothing to disclose.

\section{Author details}

'Department of Cardiology, Union Hospital, Tongji Medical College, Huazhong University of Science and Technology, Hubei Province 430022, China. ${ }^{2}$ Department of Nephrology, Wuhan HanKou Hospital, Hubei Province 430012, China. ${ }^{3}$ Department of Cardiology, Hubei No.3, People's Hospital of Jianghan University, Wuhan 43003, China. ${ }^{4}$ Key Laboratory of Metallurgical Equipment and Control Technology, Wuhan University of Science and Technology, Hubei Province 430081, China.

Received: 11 April 2021 Accepted: 5 June 2021 Published online: 15 June 2021

\section{References}

1. Harky A, Botezatu B, Kakar S, Ren M, Shirke MM, Pullan M. Mitral valve diseases: pathophysiology and interventions. Prog Cardiovasc Dis. 2021. Epub 2021/04/05. PubMed PMID: 33812859. https://doi.org/10.1016/j.pcad.2 021.03.008.

2. Lazam S, Vanoverschelde JL, Tribouilloy C, Grigioni F, Suri RM, Avierinos JF, et al. Twenty-year outcome after mitral repair versus replacement for severe degenerative mitral regurgitation: analysis of a large, prospective, multicenter. Int Registry Circ. 2017;135(5):410-22. https://doi.org/10.1161/ CIRCULATIONAHA.116.023340 Epub 2016/12/03. PubMed PMID: 27899396.

3. Altarabsheh SE, Deo SV, Dunlay SM, Erwin PJ, Obeidat YM, Navale S, et al. Meta-analysis of usefulness of concomitant mitral valve repair or replacement for moderate ischemic mitral regurgitation with coronary artery bypass grafting. Am J Cardiol. 2017;119(5):734-41. https://doi.org/10.1 016/j.amjcard.2016.11.024 Epub 2017/01/23. PubMed PMID: 28109559.

4. Michler RE, Smith PK, Parides MK, Ailawadi G, Thourani V, Moskowitz AJ, et al. Two-year outcomes of surgical treatment of moderate ischemic mitral regurgitation. N Engl J Med. 2016:374(20):1932-41. https://doi.org/10.1056/ NEJMoa1602003 Epub 2016/04/05. PubMed PMID: 27040451; PubMed Central PMCID: PMCPMC4908820.

5. Berndt J, Kloting N, Kralisch S, Kovacs P, Fasshauer M, Schon MR, et al. Plasma visfatin concentrations and fat depot-specific mRNA expression in humans. Diabetes. 2005;54(10):2911-6. Epub 2005/09/28. PubMed PMID: 16186392. https://doi.org/10.2337/diabetes.54.10.2911.

6. Kim DH, Kim C, Ding EL, Townsend MK, Lipsitz LA. Adiponectin levels and the risk of hypertension: a systematic review and meta-analysis. Hypertension. 2013;62(1):27-32. https://doi.org/10.1161/HYPERTENSIONA HA.113.01453 PubMed PMID: 23716587; PubMed Central PMCID: PMC3729220.

7. Liu JL, Zhang XJ, Zhang Z, Zhang AH, Wang W, Dong JH. Meta-analysis: prognostic value of survivin in patients with hepatocellular carcinoma. PLoS One. 2013;8(12):e83350. https://doi.org/10.1371/journal.pone.0083350 Epub 2014/01/05. PubMed PMID: 24386184; PubMed Central PMCID: PMCP MC3873280

8. Tierney JF, Stewart LA, Ghersi D, Burdett S, Sydes MR. Practical methods for incorporating summary time-to-event data into meta-analysis. Trials. 2007;8: 16. https://doi.org/10.1186/1745-6215-8-16 Epub 2007/06/09. PubMed PMID: 17555582; PubMed Central PMCID: PMCPMC1920534.

9. Parmar MK, Torri V, Stewart L. Extracting summary statistics to perform meta-analyses of the published literature for survival endpoints. Stat Med. 1998;17(24):2815-34. Epub 1999/01/28. PubMed PMID: 9921604. https://doi. org/10.1002/(SICI)1097-0258(19981230)17:24<2815::AID-SIM110>3.0.CO;2-8.

10. Le Tourneau T, de Groote P, Millaire A, Foucher C, Savoye C, Pigny P, et al. Effect of mitral valve surgery on exercise capacity, ventricular ejection fraction and neurohormonal activation in patients with severe mitral regurgitation. J Am Coll Cardiol. 2000;36(7):2263-9. Epub 2000/12/29. PubMed PMID: 11127471. https://doi.org/10.1016/S0735-1097(00)01015-9.

11. Senechal M, MacHaalany J, Bertrand OF, O'Connor K, Parenteau J, DuboisSenechal IN, et al. Predictors of left ventricular remodeling after surgical repair or replacement for pure severe mitral regurgitation caused by leaflet prolapse. Am J Cardiol. 2013;112(4):567-73. Epub 2013/05/21. PubMed PMID: 23683949. https://doi.org/10.1016/j.amjcard.2013.04.024.

12. DiGregorio V, Zehr KJ, Orszulak TA, Mullany CJ, Daly RC, Dearani JA, et al. Results of mitral surgery in octogenarians with isolated nonrheumatic mitra regurgitation. Ann Thorac Surg. 2004;78(3):807-13. https://doi.org/10.1016/j.a thoracsur.2004.03.041 discussion 13-4. PubMed PMID: 15336996. Epub 2004/ 09/01.

13. Hong JH, Schaff HV, Nishimura RA, Abel MD, Dearani JA, Li Z, et al. Mitral regurgitation in patients with hypertrophic obstructive cardiomyopathy: implications for concomitant valve procedures. J Am Coll Cardiol. 2016; 68(14):1497-504. PubMed PMID: 27687190. Epub 2016/10/01. https://doi. org/10.1016/j.jacc.2016.07.735.

14. Vassileva CM, Boley T, Markwell S, Hazelrigg S. Mitral valve repair is underused in patients with hypertrophic obstructive cardiomyopathy. Heart Surg Forum. 2011;14(6):E376-9. PubMed PMID: 22167765. Epub 2011/12/15. https://doi.org/10.1532/HSF98.20111067.

15. Helder MR, Schaff HV, Dearani JA, Li Z, Stulak JM, Suri RM, et al. Management of mitral regurgitation in Marfan syndrome: outcomes of valve repair versus replacement and comparison with myxomatous mitral valve disease. J Thorac Cardiovasc Surg. 2014;148(3):1020-4. https://doi. org/10.1016/j.jtcvs.2014.06.046 discussion 4. Epub 2014/08/19. PubMed PMID: 25129593

16. Bozbuga N, Erentug V, Kirali K, Akinci E, Yakut C. Surgical management of mitral regurgitation in patients with Marfan syndrome. J Heart Valve Dis. 2003;12(6):717-21 Epub 2003/12/09. PubMed PMID: 14658812.

17. Shafii AE, Gillinov AM, Mihaljevic T, Stewart W, Batizy LH, Blackstone EH. Changes in left ventricular morphology and function after mitral valve surgery. Am J Cardiol. 2012;110(3):403-8. https://doi.org/10.1016/j.amjcard.2 012.03.041 e3. Epub 2012/04/27. PubMed PMID: 22534055; PubMed Central PMCID: PMCPMC4717321.

18. Coutinho GF, Correia PM, Branco C, Antunes MJ. Long-term results of mitral valve surgery for degenerative anterior leaflet or bileaflet prolapse: analysis of negative factors for repair, early and late failures, and survival. Eur J Cardiothorac Surg. 2016;50(1):66-74. PubMed PMID: 26792923.Epub 2016/ 01/23. https://doi.org/10.1093/ejcts/ezv470.

19. Zalaquett R, Scheu M, Campla C, Moran S, Irarrazaval MJ, Becker P, et al. Long-term results of repair versus replacement for degenerative mitral valve regurgitation. Rev Med Chil. 2005;133(10):1139-46 Epub 2005/12/13. doi: /S0034-98872005001000002. PubMed PMID: 16341364

20. Pandis D, Grapsa J, Athanasiou T, Punjabi P, Nihoyannopoulos P. Left ventricular remodeling and mitral valve surgery: prospective study with realtime 3-dimensional echocardiography and speckle tracking. J Thorac Cardiovasc Surg. 2011;142(3):641-9. https://doi.org/10.1016/j.jtcvs.2010.11.03 O Epub 2011/02/01. PubMed PMID: 21277588.

21. Zhou YX, Leobon B, Berthoumieu P, Roux D, Glock Y, Mei YQ, et al. Longterm outcomes following repair or replacement in degenerative mitral valve disease. Thorac Cardiovasc Surg. 2010;58(7):415-21. PubMed PMID: 20922625. Epub 2010/10/06. https://doi.org/10.1055/s-0029-1240925.

22. Grapsa J, Dawson D, Pandis D, Ntalarizou E, Cheung WS, Efthimiadis I, et al. Mitral valve repair results in better right ventricular remodelling than valve replacement for degenerative mitral regurgitation: a three-dimensional echocardiographic study. Hell J Cardiol. 2012;53(4):279-86 Epub 2012/07/17. PubMed PMID: 22796815.

23. Gramaglia B, Imazio M, Checco L, Villani M, Morea M, Di Summa M, et al. Mitral valve prolapse. Comparison between valvular repair and replacement in severe mitral regurgitation. J Cardiovasc Surg. 1999;40(1):93-9 Epub 1999/ 04/30. PubMed PMID: 10221393.

24. Gillinov AM, Faber C, Houghtaling PL, Blackstone EH, Lam BK, Diaz R, et al. Repair versus replacement for degenerative mitral valve disease with coexisting ischemic heart disease. J Thorac Cardiovasc Surg. 2003;125(6): 1350-62. Epub 2003/06/28. PubMed PMID: 12830055. https://doi.org/10.101 6/S0022-5223(02)73274-1.

25. Lee EM, Shapiro LM, Wells FC. Superiority of mitral valve repair in surgery for degenerative mitral regurgitation. Eur Heart J. 1997;18(4):655-63. Epub 1997/04/01. PubMed PMID: 9129898. https://doi.org/10.1093/oxfordjournals. eurheartj.a015312.

26. Mohty D, Orszulak TA, Schaff HV, Avierinos JF, Tajik JA, EnriquezSarano M. Very long-term survival and durability of mitral valve repair for mitral valve prolapse. Circulation. 2001:104(12 Suppl 1):11-7. Epub 2001/09/25. PubMed PMID: 11568020. https://doi.org/10.1161/hc37t1. 094903.

27. Hendrix RJ, Bello RA, Flahive JM, Kakouros N, Aurigemma GP, Keaney JF, et al. Mitral valve repair versus replacement in elderly with degenerative disease: analysis of the STS adult cardiac surgery database. Ann Thorac Surg 2019;107(3):747-53. PubMed PMID: 30612990. Epub 2019/01/08. https://doi. org/10.1016/j.athoracsur.2018.09.018. 
28. Hata M, Zittermann A, Hakim-Meibodi K, Borgermann J, Gummert J. Minimally invasive mitral valve repair or replacement for degenerative mitral regurgitation. Interact Cardiovasc Thorac Surg. 2019;28(4):575-80. PubMed PMID: 30476075. Epub 2018/11/27. https://doi.org/10.1093/icvts/ivy305.

29. Shuhaiber J, Anderson RJ. Meta-analysis of clinical outcomes following surgical mitral valve repair or replacement. Eur J Cardiothorac Surg. 2007; 31(2):267-75. Epub 2006/12/19. PubMed PMID: 17175161. https://doi.org/1 0.1016/j.ejcts.2006.11.014.

30. Kouris N, Ikonomidis I, Kontogianni D, Smith P, Nihoyannopoulos P. Mitral valve repair versus replacement for isolated non-ischemic mitral regurgitation in patients with preoperative left ventricular dysfunction. A long-term follow-up echocardiography study. Eur J Echocardiogr. 2005;6(6): 435-42. PubMed PMID: 16293530. Epub 2005/11/19. https://doi.org/10.1016/ j.euje.2005.01.003.

31. Halkos ME, Kilgo P, Lattouf OM, Puskas JD, Cooper WA, Guyton RA, et al. The effect of diabetes mellitus on in-hospital and long-term outcomes after heart valve operations. Ann Thorac Surg. 2010;90(1):124-30. PubMed PMID: 20609762. Epub 2010/07/09. https://doi.org/10.1016/j.athoracsur.2010.03.111.

32. Jovin A, Oprea DA, Jovin IS, Hashim SW, Clancy JF. Atrial fibrillation and mitral valve repair. Pacing Clin Electrophysiol. 2008;31(8):1057-63. PubMed PMID: 18684264. Epub 2008/08/08. https://doi.org/10.1111/j.1540-8159.2008. 01135.x.

33. Meyer MA, von Segesser LK, Hurni M, Stumpe F, Eisa K, Ruchat P. Long-term outcome after mitral valve repair: a risk factor analysis. Eur J Cardiothorac Surg. 2007;32(2):301-7. PubMed PMID: 17561410. Epub 2007/06/15. https:// doi.org/10.1016/j.ejcts.2007.05.008.

34. Maganti K, Rigolin VH, Sarano ME, Bonow RO. Valvular heart disease: diagnosis and management. Mayo Clin Proc. 2010;85(5):483-500. https://doi. org/10.4065/mcp.2009.0706 Epub 2010/05/04. PubMed PMID: 20435842; PubMed Central PMCID: PMCPMC2861980.

35. Salis S, Mazzanti W, Merli G, Salvi L, Tedesco CC, Veglia F, et al. Cardiopulmonary bypass duration is an independent predictor of morbidity and mortality after cardiac surgery. J Cardiothorac Vasc Anesth. 2008;22(6): 814-22. PubMed PMID: 18948034. Epub 2008/10/25. https://doi.org/10.1053/ j.jvca.2008.08.004.

36. Wang Z, Zhou C, Gu H, Zheng Z, Hu S. Mitral valve repair versus replacement in patients with rheumatic heart disease. J Heart Valve Dis. 2013;22(3):333-9 Epub 2013/10/25. PubMed PMID: 24151759.

37. Obata A, Yoshikawa J, Yoshida K, Akasaka T, Yamaura Y, Shakudo M, et al. Residual, recurrent mitral regurgitation after mitral valve reconstruction: differences in lesion and operation method. J Cardiol. 1994;24(4):311-6 Epub 1994/07/01. PubMed PMID: 8057243.

\section{Publisher's Note}

Springer Nature remains neutral with regard to jurisdictional claims in published maps and institutional affiliations.

Ready to submit your research? Choose BMC and benefit from:

- fast, convenient online submission

- thorough peer review by experienced researchers in your field

- rapid publication on acceptance

- support for research data, including large and complex data types

- gold Open Access which fosters wider collaboration and increased citations

- maximum visibility for your research: over $100 \mathrm{M}$ website views per year

At $\mathrm{BMC}$, research is always in progress.

Learn more biomedcentral.com/submissions 